\title{
Key Dietary Behavioral and Environmental Factors Mediating Dietary Variety Among Japanese Adults with Spinal Cord Injury
}

\author{
Nobuyo Tsunoda ${ }^{1,2}$, Takayo Inayama ${ }^{2, *}$, Kikuko Hata ${ }^{2}$, Jun Oka $^{3}$ \\ ${ }^{1}$ Institute of Regional Vitalization Studies, Toyo University, Gunma, Japan \\ ${ }^{2}$ Graduate School of Human Health Sciences, Tokyo Metropolitan University, Tokyo, Japan \\ ${ }^{3}$ Faculty of Home Economics, Tokyo Kasei University, Tokyo, Japan \\ Email address: \\ m5s2s9@bma.biglobe.ne.jp (N. Tsunoda), tinayama@tmu.ac.jp (T. Inayama),k3.flag@gmail.com (K. Hata), \\ okajun@tokyo-kasei.ac.jp (J. Oka)
}

\section{To cite this article:}

Nobuyo Tsunoda, Takayo Inayama, Kikuko Hata, Jun Oka. Key Dietary Behavioral and Environmental Factors Mediating Dietary Variety Among Japanese Adults with Spinal Cord Injury. International Journal of Nutrition and Food Sciences. Vol. 4, No. 1, 2015 , pp. 111-117. doi: $10.11648 /$ j.ijnfs.20150401.25

\begin{abstract}
Adequate food intake is essential for health and is influenced by dietary behaviors and environments. Therefore, we examined the key behavioral and environmental factors mediating dietary variety as indicator of diet quality in a group of community-dwelling Japanese adults with spinal cord injury (SCI). This study used a cross-sectional design. We mailed a questionnaire survey to 2,731 community-dwelling Japanese adults with SCI, and responses from 841 individuals were analyzed. Dietary variety was assessed as the frequency scores of 10 foods which are major components of the Japanese diet. Correlations between the food frequency scores and dietary behavioral and environmental factors were determined by binominal logistic regression analysis. Additionally, the correlations between these scores and answers to the questions of 'What is required to choose healthy foods?' and 'Where do you get information regarding health and nutrition?' were determined using a chi-square test. High food frequency scores were positively and significantly associated with the dietary behaviors of 'Concerning yourself with nutrition and meals for your own health', 'Eating breakfast' and 'Mealtime conversation about diet/nutrition/cooking with family/friends', and 'Having family/neighbors support' in dietary environments. Regardless of the food frequency scores, 'Knowledge' was most frequently required to choose healthy foods, while the high food frequency scores were most significantly related to 'Family/friends' as sources of information about health and nutrition. Health self-management, mealtime conversation, and health promotion support from others who also provide knowledge about health and nutrition are the key factors mediating dietary variety among people with SCI.
\end{abstract}

Keywords: Dietary Variety, Dietary Behavior, Dietary Environment, Health Promotion Support, Spinal Cord

\section{Introduction}

Many patients with spinal cord injury (SCI) are discharged to a private residence after receiving acute treatment of injuries [1,2]. It is well known that the physiologic and metabolic changes that accompany SCI result in increased risk of chronic diseases at rates higher than those for the able-bodied [3]. For people with SCI, healthy diet must be essential to minimize risk of chronic diseases. However, limited information is reported about the impacts of dietary intake on body composition, metabolic profile and the incidence or mortality of diseases among community-dwelling persons with SCI [4-6]. Unfortunately, there is an absence of dietary guidelines available for these individuals and nutritional policies for persons with SCI are insufficiently implemented in Japan.

The Japanese diet has attracted considerable attention because of the long life expectancy in Japan. The Japanese Food Guide Spinning Top [7] is based on the Japanese dietary pattern. In this food guide, the categories of grain dishes (rice, bread, noodles and pasta), fish and meat dishes (meat, fish, egg and soybean dishes), vegetable dishes, fruits and milk (milk and milk products) were adopted. In dietary guidelines in Japan, a combination of various foods was advocated for 
practice of well-balanced diets [8]. Typical diets include combinations of foods, and higher dietary variety has previously been found to be associated with positive nutritional adequacy and a decreased risk of mortality [9-11]. To support an attempt to create dietary guidelines for individuals with SCI in Japan, we previously ascertained the essential items mediating dietary variety based on the Japanese Food Guide in common in the transtheoretical mode, self-efficacy, and outcome-expectancy. Specifically, we indicated that vegetable dishes, milk and milk products and fruits are key items mediating dietary variety (submitted for publication).

Food intake is known to be influenced by dietary behavioral and environmental factors in reports which mainly studied able-bodied persons [12,13]. Findings about these associations remain unknown, especially among individuals with SCI. Therefore, the purpose of this study was to ascertain the key dietary behavioral and environmental factors mediating dietary variety among a group of Japanese community-dwelling adults with SCI.

\section{Materials and Methods}

\subsection{Subjects and Procedures}

We used a cross-sectional design. The subjects were community-dwelling Japanese adults with chronic SCI who were registered members of the Spinal Injuries Japan organization (Tokyo, Japan). With permission from the organization director, we mailed a study information sheet and a questionnaire to 2,731 members in September 2011. The study information sheet explained the aims and purpose of the study, methods, advantages and disadvantages of participating in the study, as well as the management and publication of data. It also stated that the survey was anonymous and a returned questionnaire was regarded as a consent form. We received responses from 1,000 individuals, but excluded those who responses missing crucial data such as sex, age and lesion type. Finally, the responses from 841 individuals were analyzed. The response rate was $30.8 \%$.

\subsection{Questionnaire}

\subsubsection{Preparation of Questionnaire}

The questionnaire was based on a modified framework [14] of the PRECEDE-PROCEED model [15]. The original questionnaire included 8 items on quality of life, health status, dietary intake (dietary variety), dietary and health behavior, the transtheoretical model, preparation factor (knowledge, attitude, skill, self-efficacy and outcome-expectancy), dietary environment and attributes. In this study, we performed second-order analysis on the association between dietary intake (dietary variety), dietary behavior, and dietary environment. Before using this questionnaire, the questions and potential answers were evaluated for the assessment of an individual's dietary life by two registered dieticians, the director of the Spinal Injuries Japan organization, a former staff member from the Tokyo metropolitan facility for persons with handicaps and an administration officer from the association for persons with handicaps. Furthermore, the former staff member from the Tokyo metropolitan facility for persons with handicaps, the administration officer of the association for persons with handicaps and two community-dwelling individuals with SCI who were registered members of a sports club checked the questionnaire for suitability and clarity.

\subsubsection{Dietary Intake (Dietary Variety)}

Dietary intake was assessed as dietary variety; that is the frequency of intake in one day or one week of 10 foods. The 10 foods were rice, meat, fish, egg, soybeans/soybean products, dairy products, green/yellow vegetables, other vegetables, potatoes, and fruits. These foods are eaten in a daily diet in Japan and are major components of the Japanese diet which consists of grain dishes, fish and meat dishes, vegetable dishes, dairy products and fruits. The frequency of intake in one day were assessed for rice, green/yellow vegetables, and other vegetables, and that in one week were assessed for other foods. Response choices were comprised of a 4-item Likert scale scored in decreasing order of frequency (score 0-3). The food frequency score was calculated as the sum of each score for the 10 foods (total scores ranged from 0 to 30). These food frequency scores were previously confirmed to relate to the nutritional intakes calculated from the dietary records of middle-aged and elderly persons [16].

Relating to food intake, participants were asked the question: 'What is required to choose healthy foods?', and were able to choose multiple responses from the following items: 'Knowledge', 'Family/neighbor support', 'Economic strength', 'Time', 'Means of mobility', 'Skill' and 'Other'.

\subsubsection{Dietary Behavior and Environment}

In terms of dietary behaviors, participants were asked about 8 items: 'Concerning yourself with nutrition and meals for your own health', 'Cooking by yourself', 'Shopping for your own groceries', 'Eating breakfast', 'Eating breakfast with your family', 'Eating dinner with your family', 'Referring to the nutrition labels or calorie information on store displays and menus' and 'Mealtime conversation about diet/nutrition/cooking with family/friends'. In regard to the dietary environments, participants were asked about 4 items: 'Having family/neighbor support', 'Having people with whom you can learn and reflect about a healthy diet', 'Getting information related to a healthy diet at a store/restaurant' and 'Getting foods and menus that are nutritionally balanced at a store/restaurant'. Most of these questions were based on the questions asked in the National Health and Nutrition Survey in Japan [17].

Relating to dietary environments, participants were asked the question: 'Where do you get information regarding health and nutrition?', and allowed to be choose multiple answer from the following items: 'Television/newspaper', 'Family/friends', 'Medical organization', 'Internet', 'Specialized magazine/book', 'Health organization', 'Workplace/school', 'Other' and 'Not getting information'. 


\subsection{Statistical Analysis}

Nominal scales were expressed as the numbers of subjects (rate). Interval scales were expressed as the mean (standard deviation; SD) or the median (25th-75th percentile range). The associations between the attributes and the frequency scores of food intake were analyzed using the Mann-Whitney $\mathrm{U}$ test for two variables or the Kruskal-Wallis test for three or more variables.

The correlations between the food frequency scores and dietary behavioral and environmental factors were determined using binominal logistic regression analysis. The dependent variables were the food frequency scores, and the independent variables were dietary behaviors and environments. Based on the median, the food frequency scores were divided into subgroups, including the superior group $(>16)$ and the subordinate group $(\leq 16)$. The former was scored as 1 and the latter was scored as 0 . In addition, in consideration of the distribution, positive answers in dietary behavioral and environmental factors were scored as 1 and negative answers were scored as 0 . Variables were applied by compulsive injection into the calculation of univariate and multivariate analyses. These analyses were adjusted by sex, age classification, time after injury, lesion type, living alone or with other persons, having a job, receiving public nursing care services, and social participation. In addition, dietary behaviors (Model 1) or dietary environments (Model 2) were applied in order of each model. The results were expressed as the odds ratio (OR) and $95 \%$ confidence interval $(\mathrm{CI})$.

In the questions: 'What is required to choose healthy foods?' and 'Where do you get information regarding health and nutrition?', instances where there was no response (missing answers) were excluded. The association between persons who selected and did not select each item, and the food frequency scores subgroups were determined using the chi-squared test.

All statistical analyses were performed using IBM SPSS Statistics v.19 (IBM Japan Inc., Tokyo, Japan). Statistical significance was set at $P<0.05$ for two-tailed tests.

\subsection{Statement of Ethics}

This study was approved by the ethical committee of Tokyo Metropolitan University.

\section{Results}

Subjects' mean age was 61.6 (SD 11.5) years for men and 57.8 (SD 13.1) years for women. Mean time after injury was

Table 1. Characteristics of Japanese individuals with spinal cord injuries.

\begin{tabular}{|c|c|c|c|c|c|c|}
\hline \multirow{2}{*}{ Variables $^{\mathrm{a}}$} & \multirow{2}{*}{ Groups } & \multicolumn{2}{|c|}{ Whole sample $n=841$} & \multicolumn{2}{|c|}{ Food frequency scores } & \multirow{2}{*}{$\mathbf{P}^{\mathbf{c}}$} \\
\hline & & $\mathbf{n}$ & $(\%)$ & Median & 25th-75th percentile range & \\
\hline \multirow[t]{2}{*}{ Sex } & Men & 718 & $(85.4)$ & 16.0 & $(12.0-20.0)$ & 0.002 \\
\hline & Women & 123 & $(14.6)$ & 18.0 & $(14.0-21.0)$ & \\
\hline \multirow[t]{4}{*}{ Age classification } & $\leq 49$ Years & 150 & $(17.8)$ & 16.0 & $(10.8-19.0)$ & $<0.001$ \\
\hline & $50-59$ Years & 176 & $(20.9)$ & 15.0 & $(12.0-18.8)$ & \\
\hline & $60-69$ Years & 301 & $(35.8)$ & 16.0 & $(13.0-20.0)$ & \\
\hline & $\geq 70$ Years & 214 & $(25.5)$ & 18.5 & $(14.0-21.3)$ & \\
\hline \multirow[t]{3}{*}{ Lesion type } & Cervical cord injury & 245 & $(29.1)$ & 16.0 & $(12.0-20.0)$ & 0.870 \\
\hline & Thoracic cord injury & 434 & $(51.6)$ & 16.0 & $(12.8-20.0)$ & \\
\hline & Lumbar cord injury & 162 & $(19.3)$ & 16.5 & $(13.0-20.0)$ & \\
\hline \multirow[t]{5}{*}{ Time after injury } & $\leq 9$ Years & 78 & $(9.8)$ & 17.0 & $(12.0-20.0)$ & 0.26 \\
\hline & 10-19 Years & 162 & $(20.2)$ & 16.0 & $(12.0-20.0)$ & \\
\hline & $20-29$ Years & 178 & $(22.2)$ & 16.0 & $(12.0-20.0)$ & \\
\hline & $30-39$ Years & 219 & $(27.4)$ & 17.0 & $(13.0-20.0)$ & \\
\hline & $\geq 40$ Years & 163 & $(20.4)$ & 17.0 & $(13.0-20.0)$ & \\
\hline \multirow[t]{2}{*}{ Living alone or with other persons } & Alone & 99 & (11.8) & 14.0 & $(11.0-18.0)$ & $<0.001$ \\
\hline & With other persons & 742 & $(88.2)$ & 17.0 & $(13.0-20.0)$ & \\
\hline \multirow[t]{2}{*}{ Social participation } & Presence & 536 & $(68.9)$ & 16.0 & $(13.0-20.0)$ & 0.03 \\
\hline & Absence & 242 & $(31.1)$ & 15.0 & $(11.0-20.0)$ & \\
\hline \multirow[t]{2}{*}{ Having a job } & Have & 224 & $(28.4)$ & 15.5 & $(12.0-19.0)$ & 0.04 \\
\hline & Have not & 566 & $(71.6)$ & 16.0 & $(13.0-20.0)$ & \\
\hline \multirow[t]{2}{*}{ Receiving of public nursing care services } & Receiving & 287 & $(37.8)$ & 17.0 & $(13.0-21.0)$ & 0.005 \\
\hline & Not receiving & 472 & $(62.2)$ & 16.0 & $(12.0-20.0)$ & \\
\hline
\end{tabular}

${ }^{\text {a }}$ Missing answers were excluded.

${ }^{\mathrm{b}}$ Response choices of 10 foods (rice, meat, fish, egg, soybeans/soybean products, dairy products, green/yellow vegetables, other vegetables, potatoes and fruits) comprised a 4-item Likert scale and were scored in decreasing order of frequency (score 0-3). The food frequency score was calculated as the sum of each score for the 10 foods (total score ranged from 0 to 30 ).

${ }^{\mathrm{c}}$ The food frequency scores by the attributes were analyzed by Mann-Whitney test for two variables or Kruskal-Wallis test for three or more variables.

27.6 (SD 12.8) years for men and 25.9 (SD 14.4) years for women. Other subject characteristics are shown in Table 1. About half of the subjects (51.6\%) had thoracic cord injury, and $29.1 \%$ had cervical cord injury.

The mean and median food frequency scores were 16.3 (SD
5.1) and 16.0, respectively. The food frequency scores between the superior group and the subordinate group were significantly different depending on sex, age classification, living alone or with other persons, social participation, having a job, and receiving public nursing care services. 
Table 2. Correlations between food frequency scores subgroups and dietary behavioral and environmental factors among Japanese adults with spinal cord injuries.

\begin{tabular}{|c|c|c|c|c|c|c|c|c|c|c|c|}
\hline \multirow{4}{*}{ Variables $^{\mathrm{a}}$} & \multirow{4}{*}{ Groups } & \multicolumn{4}{|c|}{ Food frequency scores subgroups } & \multicolumn{3}{|c|}{ Univariate analysis $^{\mathrm{c}}$} & \multicolumn{3}{|c|}{ Multivariate analysis $^{\mathrm{c}}$} \\
\hline & & \multirow{2}{*}{\multicolumn{2}{|c|}{$\begin{array}{l}\text { Superior group }^{\mathrm{b}} \\
\mathrm{n}=413\end{array}$}} & \multirow{2}{*}{\multicolumn{2}{|c|}{$\begin{array}{l}\text { Subordinate } \\
\text { group }^{\mathbf{b}}\end{array}$}} & \multirow{3}{*}{\multicolumn{2}{|c|}{ OR $(95 \% C I)^{d}$}} & \multirow{3}{*}{$\mathbf{P}$} & \multirow{3}{*}{\multicolumn{2}{|c|}{$\operatorname{OR}(95 \% \mathrm{CI})^{\mathrm{d}}$}} & \multirow{3}{*}{$\mathbf{P}$} \\
\hline & & & & & & & & & & & \\
\hline & & $\mathbf{n}$ & $(\%)$ & $\mathbf{n}$ & $(\%)$ & & & & & & \\
\hline \multicolumn{12}{|l|}{ Dietary behavior [ Model 1 ] } \\
\hline \multirow{2}{*}{$\begin{array}{l}\text { Concerning yourself with nutrition } \\
\text { and meals for your own heath }\end{array}$} & Very often/quit & 282 & $(70.0)$ & 182 & $(43.1)$ & 2.94 & $(2.11-4.10)$ & $<0.001$ & 2.44 & $(1.68-3.55)$ & $<0.001$ \\
\hline & Other & 121 & $(30.0)$ & 240 & $(56.9)$ & 1 & & & 1 & & \\
\hline \multirow[t]{2}{*}{ Cooking by yourself } & $\begin{array}{l}\text { Always/sometimes } \\
\text { /not always }\end{array}$ & 216 & (53.6) & 256 & $(60.7)$ & 0.74 & $(0.52-1.04)$ & 0.08 & 0.68 & $(0.45-1.04)$ & 0.07 \\
\hline & Other & 187 & $(46.4)$ & 166 & $(39.3)$ & 1 & & & 1 & & \\
\hline \multirow[t]{2}{*}{ Shopping for your own groceries } & $\begin{array}{l}\text { Not less than } \\
\text { once a month }\end{array}$ & 227 & $(55.5)$ & 267 & $(62.8)$ & 0.83 & $(0.59-1.17)$ & 0.28 & 0.99 & $(0.66-1.50)$ & 0.97 \\
\hline & Other & 182 & $(44.5)$ & 158 & $(37.2)$ & 1 & & & 1 & & \\
\hline \multirow{2}{*}{ Eating breakfast } & Always & 361 & $(89.8)$ & 302 & $(71.6)$ & 2.81 & $(1.83-4.31)$ & $<0.001$ & 2.34 & $(1.41-3.88)$ & 0.001 \\
\hline & Other & 41 & $(10.2)$ & 120 & $(28.4)$ & 1 & & & 1 & & \\
\hline \multirow{2}{*}{ Eating breakfast with your family } & Always & 261 & $(65.2)$ & 185 & $(43.8)$ & 1.89 & $(1.33-2.69)$ & $<0.001$ & 1.18 & $(0.74-1.90)$ & 0.48 \\
\hline & Other & 139 & $(34.8)$ & 237 & $(56.2)$ & 1 & & & 1 & & \\
\hline \multirow{2}{*}{ Eating dinner with your family } & Always & 301 & $(75.2)$ & 271 & $(64.2)$ & 1.17 & $(0.79-1.74)$ & 0.43 & 0.67 & $(0.41-1.10)$ & 0.12 \\
\hline & Other & 99 & $(24.8)$ & 151 & $(35.8)$ & 1 & & & 1 & & \\
\hline \multirow{2}{*}{\multicolumn{2}{|c|}{$\begin{array}{l}\text { Referring to the nutrition labels or Always/sometimes } \\
\text { calorie information on store } \\
\text { displays and menus }\end{array}$}} & 183 & $(46.3)$ & 160 & $(39.2)$ & 1.10 & $(0.79-1.53)$ & 0.57 & 0.77 & $(0.53-1.13)$ & 0.18 \\
\hline & & 212 & (53.7) & 248 & $(60.8)$ & 1 & & & 1 & & \\
\hline \multirow{2}{*}{\multicolumn{2}{|c|}{$\begin{array}{ll}\begin{array}{l}\text { Mealtime conversation } \\
\text { diet/nutrition/cooking }\end{array} & \text { about Always/sometimes } \\
\text { family/friends } & \end{array}$}} & 292 & $(76.4)$ & 210 & $(50.8)$ & 2.56 & $(1.80-3.64)$ & $<0.001$ & 2.28 & $(1.53-3.40)$ & $<0.001$ \\
\hline & & 90 & $(23.6)$ & 203 & $(49.2)$ & 1 & & & 1 & & \\
\hline \multicolumn{12}{|c|}{ Dietary environment [ Model 2 ] } \\
\hline \multicolumn{2}{|c|}{ Having family/neighbour support Always } & 272 & $(67.2)$ & 168 & $(40.4)$ & 2.57 & $(1.84-3.60)$ & $<0.001$ & 2.37 & $(1.67-3.38)$ & $<0.001$ \\
\hline for your health promotion & Other & 133 & $(32.8)$ & 248 & $(59.6)$ & 1 & & & 1 & & \\
\hline \multirow{2}{*}{$\begin{array}{l}\text { Having people with whom you can } \\
\text { learn and reflect about a healthy } \\
\text { diet }\end{array}$} & Have a lot of $/ a$ few & 191 & $(47.3)$ & 129 & $(31.2)$ & 1.73 & $(1.24-2.41)$ & 0.001 & 1.31 & $(0.91-1.90)$ & 0.14 \\
\hline & Other & 213 & $(52.7)$ & 285 & $(68.8)$ & 1 & & & 1 & & \\
\hline \multirow{4}{*}{\multicolumn{2}{|c|}{$\begin{array}{l}\text { Getting information related to a Enough/quite/a little } \\
\text { healthy diet at a store/restaurant Other } \\
\text { Getting foods and menus that are Enough/quite/a little } \\
\text { nutritionally balanced at a Other } \\
\text { store/restaurant }\end{array}$}} & 196 & $(50.6)$ & 163 & $(40.1)$ & 1.41 & $(1.02-1.95)$ & 0.04 & 1.45 & $(0.88-2.37)$ & 0.15 \\
\hline & & 191 & $(49.4)$ & 243 & $(59.9)$ & 1 & & & 1 & & \\
\hline & & 217 & $(55.9)$ & 183 & $(45.2)$ & 1.24 & $(0.90-1.71)$ & 0.20 & 0.81 & $(0.49-1.32)$ & 0.39 \\
\hline & & 171 & $(44.1)$ & 222 & (54.8) & 1 & & & 1 & & \\
\hline
\end{tabular}

OR, odds ratio; CI, confidence interval.

${ }^{a}$ Missing answers were excluded.

${ }^{\mathrm{b}}$ Response choices of 10 foods (rice, meat, fish, egg, soybeans/soybean products, dairy products, green/yellow vegetables, other vegetables, potatoes and fruits) comprised a 4-item Likert scale and were scored in decreasing order of frequency (score 0-3). The food frequency score was calculated as the sum of each score for the 10 foods (total score ranged from 0 to 30). Based on the median, the food frequency score was divided into subgroups including the superior group $(>16)$ and the subordinate group $(\leq 16)$. The former was scored as 1 and the latter was scored as 0 . In addition, positive answers in dietary behavioral and environmental factors were scored as 1 , and negative answers were scored as 0 in consideration of their distribution.

${ }^{\mathrm{c}}$ Binominal logistic regression analysis was performed. The dependent variables were the frequency sores of food intake, and the independent variables were dietary behavioral and environmental factors. Variables were applied by compulsive injection into the calculation of univariate and multivariate analyses. These analyses were adjusted by sex, age classification, time after injury, lesion type, living alone or with other persons, having a job, receiving of public nursing care services and social participation. Moreover, each dependent variable group including dietary behavior (Model 1) and dietary environment (Model 2) were respectively applied.

d 'Other' is a reference variable. An odds ratio of more than 1 indicates a higher frequency score of food intake.

The correlations between the food frequency scores and dietary behavioral and environmental factors were determined by binominal logistic regression analysis (Table 2). In the univariate analysis, the high food frequency scores were positively and significantly associated with 'Concerning yourself with nutrition and meals for your own health', 'Eating breakfast', 'Eating breakfast with your family' and 'Mealtime conversation about diet/nutrition/cooking with family/friends' in dietary behaviors, and 'Having family/neighbors support', 'Having people with whom you can learn and reflect about a healthy diet' and 'Getting information related to a healthy diet at store/restaurant' in dietary environments. In the multivariate analysis, 'Eating breakfast with your family' in dietary behaviors, and 'Having people with whom you can learn and reflect about a healthy diet' and 'Getting information related to a healthy diet at a store/restaurant' in dietary environments became non-significant.

The association between the food frequency scores and the answers of the questions: 'What is required to choice healthy 
foods?' and 'Where do you get information regarding health and nutrition?' were determined using the chi-square test (Table 3 ). In the former question, more than half participants answered 'Knowledge' regardless of the food frequency scores. Subsequently, about 25-30\% answered 'Family/neighbor support'. In the latter question, participants in the superior group answered 'Family/friends', 'Medical organization' and 'Health organization' significantly more than those in the subordinate group, but answered 'Not getting information' significantly less. About 70\% answered 'Television/newspaper', however, a significant difference was not shown between subgroups in the food frequency scores for this item.

Table 3. Correlations between food frequency scores subgroups and answers about what is required to choose healthy foods and information sources about health/nutrition among Japanese adults with spinal cord injuries.

\begin{tabular}{|c|c|c|c|c|c|}
\hline \multirow{4}{*}{ Question and answers ${ }^{\mathrm{a}}$} & \multicolumn{5}{|c|}{ Food frequency scores subgroups } \\
\hline & \multirow{2}{*}{\multicolumn{2}{|c|}{$\begin{array}{l}\text { Superior group }^{b} \\
n=413\end{array}$}} & \multicolumn{2}{|c|}{ Subordinate group $^{b}$} & \multirow{3}{*}{$\mathbf{P}^{\mathbf{c}}$} \\
\hline & & & $\mathrm{n}=4$ & & \\
\hline & $\mathbf{n}$ & (\% in superior group) & $\mathbf{n}$ & (\% in subordinate group) & \\
\hline \multicolumn{6}{|c|}{ What is required to choose healthy foods? } \\
\hline Knowledge & 213 & $(55.5)$ & 231 & $(55.8)$ & 0.94 \\
\hline Family/neighbour support & 108 & $(28.1)$ & 123 & $(29.7)$ & 0.64 \\
\hline Economic strength & 78 & $(20.3)$ & 83 & $(20.0)$ & 0.93 \\
\hline Means of mobility & 40 & $(10.4)$ & 44 & $(10.6)$ & 1.00 \\
\hline Skill & 13 & $(3.4)$ & 21 & $(5.1)$ & 0.29 \\
\hline Other & 16 & $(4.2)$ & 23 & $(5.6)$ & 0.41 \\
\hline \multicolumn{6}{|c|}{ Where do you get information regarding health and nutrition? } \\
\hline Television/newspaper & 288 & $(72.5)$ & 306 & $(74.8)$ & 0.47 \\
\hline Family/friends & 215 & $(54.2)$ & 167 & $(40.8)$ & $<0.001$ \\
\hline Medical organisation & 196 & $(49.4)$ & 169 & $(41.3)$ & 0.02 \\
\hline Specialized magazine/book & 73 & $(18.4)$ & 63 & $(15.4)$ & 0.26 \\
\hline Health organisation & 44 & $(11.1)$ & 23 & $(5.6)$ & 0.007 \\
\hline Workplace/school & 17 & $(4.3)$ & 8 & $(2.0)$ & 0.07 \\
\hline Other & 13 & $(3.3)$ & 12 & $(2.9)$ & 0.84 \\
\hline Not getting information & 19 & $(4.8)$ & 34 & $(8.3)$ & 0.047 \\
\hline
\end{tabular}

Multiple answered allowed.

${ }^{\text {a }}$ No responses (missing answers) were excluded.

${ }^{\mathrm{b}}$ Response choices of 10 foods (rice, meat, fish, egg, soybeans/soybean products, dairy products, green/yellow vegetables, other vegetables, potatoes and fruits) comprised a 4-item Likert scale and were scored in decreasing order of frequency (score 0-3). The food frequency score was calculated as the sum of each score for the 10 foods (total score ranged from 0 to 30). Based on the median, the food frequency sore was divided into subgroups including the superior group $(>16)$ and the subordinate group $(\leq 16)$.

${ }^{\mathrm{c}}$ The association between persons who selected and did not select each item, and food frequency scores subgroups were determined using the chi-squared test.

\section{Discussion}

Our results suggest that self-management for health, eating breakfast, mealtime conversation, and health promotion support from others who also provide knowledge about health and nutrition are key factors mediating dietary variety among people with SCI. To our knowledge, ours is the first study showing the relationships between dietary variety and dietary behavioral and environmental factors among persons with SCI Therefore, these results are helpful in facilitating guidelines and policies that support health promotion for individuals with SCI.

The behavioral factors associated with dietary variety were self-management for health, eating breakfast and mealtime conversation (Table 2, Model 1). 'Concerning yourself with nutrition and meals for your own health' is a broadly representative item of preferred dietary behavior. This study indicated that people who replied in the affirmative to this question had healthy eating habits. On the other hand, it is not yet been clear whether mealtime conversation promotes better food intake even among able-bodied persons. However, previous studies have demonstrated that more frequent family meals were associated with higher intakes of fruit, vegetables and calcium-rich foods among children [18], and adolescents $[19,20]$. The role of mealtime conversation among individuals with SCI should be further investigated.

In our study, the positive relationships between dietary variety and eating breakfast could have been caused by the survey method for dietary variety. Specifically, people who eat breakfast eat more meals than those who do not. Consequently, food intake become more frequent and the food frequency scores become higher. Further studies are needed to investigate this association among people with SCI.

The environmental factor associated with dietary variety was family/neighbor that support health promotion (Table 2, Model 2). Prior reports among able-bodied people found social support to be correlated with positive change in fruit and vegetable consumption [21-23] and negative change in fat consumption [24]. Although research on a psychosocial approach to health has recently been conducted for persons with SCI, there was no direct evidence for the relationships between dietary variety and environmental factors [25-27]. Based on the results of the current study and previous reports among able-bodied persons, social support must be an important factor in promoting higher dietary variety among 
both able-bodied persons as well as those with SCI. However, in the National Nutrition Survey (present National Health and Nutrition Survey after the revision) in Japan, $23.0 \%$ of abele-bodied people had family support for health promotion [28], while in the current study $53.6 \%$ of people with SCI had support. This difference in rates may be due to differences in supports that people with SCI had relative to those that are able-bodied. Hence, it is important to clarify what supports people with SCI need and whether supports promote dietary variety.

In the answers to question of what required to choose healthy foods, 'Knowledge' was the most frequent answer, and 'Family/neighbor support' was the second (Table 3). These answers did not differ depend on the food frequency scores, and might be common crucial factors for persons with SCI. In a review, Shaikh et al indicated that self-efficacy, social support and knowledge were strong positive predictors of adults' fruit and vegetable intake [29]. In another review, Spronkl et al also showed that the majority of studies reported an association between higher nutrition knowledge and higher intake of fruit and vegetables [30]. Similarly, social support and knowledge were cited in this study as mediators of dietary variety among individuals with SCI. Thus, we examined where individuals might acquire the knowledge of health and nutrition. Regardless of the food frequency scores, the most frequently answer was 'Television/newspaper'. However, persons in the superior group answered 'Family/friends', 'Medical organization' and 'Health organization' significantly more frequently than those in the subordinate group. This showed that most persons who intake various foods get information regarding health and nutrition from neighbors and/or formal organizations. Conversely, fewer of these individuals answered 'Not getting information'. These results suggest that attempting to provide a space for getting knowledge about health and nutrition with neighbors is important to mediate dietary variety. Furthermore, we should have policies where substantial information is provided by medical and health organizations frequently utilized by individuals with SCI.

This study has a number of limitations. First, all SCI recruited participants were members of the Spinal Injuries Japan organization. Additionally, foods, dietary behaviors and dietary environments differ depending upon country and ethnic group. Therefore, our findings may not be representative of the overall chronic SCI population in Japan and other countries. Second, the food frequency scores used in this study cannot estimate the quantity of food intake. The quantity of foods which are major components of the Japanese diet to prevent the chronic diseases and maintain health for individuals with SCI needs to be confirmed in further studies.

\section{Conclusions}

This study found that health self-management, mealtime conversation and people that health promotion support from others who also provide knowledge about health and nutrition are key factors mediating dietary variety for community-dwelling Japanese people with SCI. Dietary guidelines promoting health self-management and mealtime conversation for individuals with SCI should be produced to support health maintenance. Furthermore, policies that facilitate the mutually supportive system and the learning areas should be implemented in the community among persons with SCI. Moreover, substantial evidence related to our research should be gathered in many countries. This will enable confirmation of whether or not our findings are common to people with SCI worldwide, or are specific to people with SCI in Japan.

\section{Acknowledgments}

We thank all of the SCI individuals who participated in this study. This work was supported by JSPS KAKENHI Grant Number 23500962.

\section{References}

[1] Tsurumi K, Isaji T, Ohnaka K. Multifaceted analysis of factors affecting home discharge of patients with cervical spinal cord injury. Jpn J Rehabil Med. 2012; 49:726-733. (in Japanese) https://www.jstage.jst.go.jp/article/jjrmc/49/10/49_726/_pdf (accessed December 2014).

[2] Public resources for National spinal cord injury statistical center (2013) Annual Report for the spinal cord injury model systems. https://www.nscisc.uab.edu/ (accessed December 2014).

[3] Garshick E, Kelley A, Cohen SA, Garrison A, Tun CG, Gagnon D, Brown R. A prospective assessment of mortality in chronic spinal cord injury. Spinal Cord. 2005; 43:408-416.

[4] Groah SL, Nash MS, Ljungberg IH, Libin A, Hamm LF, Ward E, Burns PA, Enfield G. Nutrient intake and body habitus after spinal cord injury: an analysis by sex and level of injury. J Spinal Cord Med. 2009; 32:25-33.

[5] Moussavi RM, Ribas-Cardus F, Rintala DH, Rodriguez GP. Dietary and serum lipids in individuals with spinal cord injury living in the community. J Rehabil Res Dev. 2001; $38: 225-233$

[6] Bloemen-Vrencken JH, de Witte LP, Post MW, van den Heuvel WJ. Health behavior of persons with spinal cord injury. Spinal Cord. 2007; 45:243-249.

[7] Yoshiike N, Hayashi F, Takemi Y, Mizoguchi K, Seino F. A new food guide in Japan: the Japanese food guide Spinning Top. Nutr Rev. 2007; 65:149-154.

[8] The Japan Dietetic Association (2000) The JDA news letter on web: Japan's Dietary Guidelines. http://www.dietitian.or.jp/english/newsletter/jpndiet.html (accessed December 2014).

[9] Kant AK, Schatzkin A, Block G, Ziegler RG, Nestle M. Food group intake patterns and associated nutrient profiles of the US population. J Am Diet Assoc. 1991; 91:1532-1537.

[10] Murphy SP, Foote JA, Wilkens LR, Basiotis PP, Carlson A, White KK, Yonemori KM. Simple measures of dietary variety are associated with improved dietary quality. J Am Diet Assoc. 2006; 106:425-429. 
[11] Kant AK, Schatzkin A, Harris TB, Ziegler RG, Block G. Dietary diversity and subsequent mortality in the First National Health and Nutrition Examination Survey Epidemiologic Follow-up Study. Am J Clin Nutr. 1993; 57:434-440.

[12] Ammerman AS, Lindquist $\mathrm{CH}$, Lohr $\mathrm{KN}$, Hersey J. The efficacy of behavioral interventions to modify dietary fat and fruit and vegetable intake: a review of the evidence. Prev Med. 2002; 35:25-41.

[13] Larson N, Story M. A review of environmental influences on food choices. Ann Behav Med. 2009; 38 Suppl 1:S56-73.

[14] Ministry of Health, Labour and Welfare (2012) A Basic Direction for Comprehensive Implementation of National Health Promotion. http://www.mhlw.go.jp/file/06-Seisakujouhou-10900000-Ken koukyoku/0000047330.pdf (accessed January 2015).

[15] Green LW, Kreuter MW. Health program planning: an educational and ecological approach. 4th ed. Boston: Mc Graw Hill; 2005.

[16] Mizoguchi K, Takemi Y, Adachi M. Relationship between a positive perception toward work and the dietary habits of young male workers. Jpn J Nutr Diet. 2004; 62:269-283. (in Japanese)

https://www.jstage.jst.go.jp/article/eiyogakuzashi1941/62/5/62 _5_269/_pdf(accessed December 2014).

[17] Ministry of Health Labour and Welfare, National Health and Nutrition http://www.mhlw.go.jp/toukei/itiran/gaiyo/k-eisei.html (accessed December 2014).

[18] Haapalahti M, Mykkänen H, Tikkanen S, Kokkonen J. Meal patterns and food use in 10- to 11-year-old Finnish children. Public Health Nutr. 2003; 6:365-370.

[19] Videon TM, Manning CK. Influences on adolescent eating patterns: the importance of family meals. J Adolesc Health. $2003 ; 32: 365-373$.

[20] Neumark-Sztainer D, Hannan PJ, Story M, Croll J, Perry C. Family meal patterns: associations with sociodemographic characteristics and improved dietary intake among adolescents. J Am Diet Assoc. 2003; 103:317-322.
[21] Langenberg P, Ballesteros M, Feldman R, Damron D, Anliker J, Havas S. Psychosocial factors and intervention-associated changes in those factors as correlates of change in fruit and vegetable consumption in the Maryland WIC 5 A Day Promotion Program. Ann Behav Med. 2000; 22:307-315.

[22] O'Neal CW, Wickrama KA, Ralston PA, Ilich JZ, Harris CM, Coccia C, Young-Clark I, Lemacks J. Examining change in social support and fruit and vegetable consumption in African American adults. J Nutr Health Aging. 2014; 18:10-14.

[23] Sorensen G, Stoddard AM, Dubowitz T, Barbeau EM, Bigby J, Emmons KM, Berkman LF, Peterson KE. The influence of social context on changes in fruit and vegetable consumption: results of the healthy directions studies. Am J Public Health. 2007; 97:1216-1227.

[24] Lloyd HM, Paisley CM, Mela DJ. Barriers to the adoption of reduced-fat diets in a UK population. J Am Diet Assoc. 1995; 95:316-322.

[25] Müller R, Peter C, Cieza A, Geyh S. The role of social support and social skills in people with spinal cord injury--a systematic review of the literature. Spinal Cord. 2012; 50:94-106.

[26] Post MW, van Leeuwen CM. Psychosocial issues in spinal cord injury: a review. Spinal Cord. 2012; 50:382-389.

[27] Guilcher SJ, Casciaro T, Lemieux-Charles L, Craven C, McColl MA, Jaglal SB. Social networks and secondary health conditions: the critical secondary team for individuals with spinal cord injury. J Spinal Cord Med. 2012; 35:330-342.

[28] Ministry of Health, Labour and Welfare (1999) Summary of National Health and Nutrition Survey in Japan. http://www.mhlw.go.jp/houdou/0103/h0309-7.html (accessed December 2014).

[29] Shaikh AR, Yaroch AL, Nebeling L, Yeh MC, Resnicow K. Psychosocial predictors of fruit and vegetable consumption in adults a review of the literature. Am J Prev Med. 2008; 34:535-543.

[30] Spronk I, Kullen C, Burdon C, O'Connor H. Relationship between nutrition knowledge and dietary intake. Br J Nutr. 2014; 111:1713-1726. 